\title{
Effects of ascorbic acid on the skeletal response of chicks to vitamin D deficiency*
}

\author{
BY P. A. THORNTON \\ Veterans Administration Hospital, Lexington, Kentucky, \\ Departments of Physiology and Biophysics and of Medicine, \\ University of Kentucky, Lexington, Kentucky, USA \\ (Received 23 May 1967-Accepted 22 September 1967)
}

\begin{abstract}
I. The skeletal response of vitamin D-deficient chicks to dietary ascorbic acid was tested.
2. The epiphyseal cartilaginous plate width, which was increased by the vitamin D deficiency, was further increased when ascorbic acid was added and the effect appeared sooner. 3. Absence of vitamin $D$ was associated with a reduction in the relative amount of cancellous to compact bone ash in the tibia. Dietary ascorbic acid intensified this effect to a significant degree.

4. Plasma ascorbic acid levels in rachitic chicks were approximately $25 \%$ less than in controls. This observation may explain the skeletal response to added vitamin $\mathrm{C}$ and suggests that avian bone tissue has a particularly high requirement for this vitamin.
\end{abstract}

The skeletal response to vitamin $\mathrm{D}$ deficiency in most animal species is expressed by an apparent decrease in bone ash. The mode of action by which this deficiency causes the effect has not been clearly elucidated, but available evidence suggests that both the intestinal and skeletal systems are involved (Neuman \& Neuman, 1958). Little interest has been shown in the possible metabolic relationships between vitamin $\mathrm{D}$ and other vitamins in bone tissue. However, Thornton \& Brownrigg (196r) presented evidence which suggested that in vitamin D-deficient chicks there is an increased biological turnover of bone ${ }^{45} \mathrm{Ca}$ attributable to an effect of ascorbic acid.

The present study concerns the skeletal response of chicks to vitamin D deficiency in the absence and presence of dietary ascorbic acid. Addition of ascorbic acid to the rachitogenic diet appeared to hasten the appearance of some rachitic signs and altered the relative amounts of cancellous and compact bone ash in the tibia.

\section{EXPERIMENTAL}

Procedure. Four experiments were conducted using a similar strain of male Leghorn chicks. In each experiment the animals were given the experimental diets at I day of age. The control diet (Thornton, Weber \& Moreng, 1959) was tested before these studies and found to support growth to 2 weeks of age for this particular strain at a level nearly equal to the Animal Nutrition Research Council (ANRC) chick reference diet (Briggs, Combs, Friedman, Fritz, Lillie, Nelson, Quackenbush \& Titus, 1956). The ANRC diet is considered to meet all growth requirements. The adequacy of the control diet, without added vitamin $\mathrm{D}$, for inducing clinical signs of rickets had pre-

* This study was partially supported by funds granted by National Institute of Health (AM-09709or). 
viously been shown (Thornton $e$ t al. 1959). Both feed and water were supplied ad lib. throughout. The chicks were kept in electrically heated batteries and recommended management procedures were followed.

Expt I. For the first experiment single groups of twenty chicks were given three separate dietary treatments for 2 weeks. Each of these diets contained approximately $\mathrm{r} \cdot 00$ and $0.68 \%$ calcium and phosphorus respectively; 300 i.u. cholecalciferol $/ \mathrm{kg}$ diet were added to the control diet. The two remaining diets contained no vitamin $\mathrm{D}$; ascorbic acid was added at a level of $44 \mathrm{mg} / \mathrm{kg}$ to one of them.

The animals were weighed weekly and ten individuals per treatment were killed each week for bone studies. The right tibia was removed and cleaned of all adhering soft tissue. Care was taken to keep both articular cartilages intact. The tibia was split lengthwise and the width of the epiphyseal cartilaginous plate was determined. This measurement was made under a magnifying glass, by means of a divider and metric rule; several measurements were made on each sample and the calculated mean was used for the final value. The person making the measurements was given samples selected by others and was never aware of the group to which the sample belonged. A calculation of the correlation coefficient between plate width and tibia ash weight revealed a highly significant inverse relationship for both rachitic groups at 2 weeks $(r=-0.917)$, attesting to the reliability of the method. The samples were then ashed at $65^{\circ}$ overnight; the ash was weighed and the tibia ash per 100 $\mathrm{g}$ body-weight was calculated.

Expt 2. Four groups of twenty chicks each were used in the second experiment. The first three dietary treatments were similar to those used in Expt $\mathrm{I}$. In addition one group given the rachitogenic diet was given ascorbic acid at a higher level $(220 \mathrm{mg} / \mathrm{kg}$ diet). After 44 days the animals were killed; the left tibia was removed and compact tissue taken from it. The sample was cleaned, dried, ether-extracted for $6 \mathrm{~h}$ and dried to constant weight at $105^{\circ}$. Percentage bone ash was determined on a portion of the sample by ashing overnight at $65^{\circ}$. Citric acid (Natelson, Pincus \& Lugovoy, I948) and hydroxyproline (Martin \& Axelrod, 1953) were determined on the remaining bone tissue.

Expt 3. The third experiment was conducted to answer the following questions which were raised by the results of the earlier studies. Does vitamin $C$ reduce bone ash per unit of body-weight when added to a rachitogenic diet? Does it increase the width of the epiphyseal plate? Is the percentage ash in cortical bone increased? Are bone dimensions altered by vitamin C? Three groups of chicks (twenty/group) were given a control, a rachitogenic and a similarly deficient diet supplemented with ascorbic acid $(220 \mathrm{mg} / \mathrm{kg})$. All experimental procedures were similar to those in Expt I.

Ten chicks from each group were killed on the 7 th and 14 th days. The epiphyseal plate width of the right tibia was determined as previously described. Tibia length was measured using the distal side of the epiphyseal plate and the distal condyle as reference points. The cancellous and compact regions of the tibia were carefully separated and prepared for the determination of ash percentage as described in Expt 2. Just before being killed, following a $12 \mathrm{~h}$ fast, the chicks were weighed and the values were used for determining the amount of tibia ash per unit body-weight. 
Expt 4. A final experiment involving only the analysis of plasma for ascorbic acid was conducted with I4-day-old chicks given diets similar to those used in Expt 3 . Blood for this assessment was collected by cardiac puncture and the vitamin $\mathrm{C}$ determined by the procedure of Roe \& Kuether (1943).

Statistical treatment of the results. All statistical comparisons were made between mean values obtained on chicks given the rachitogenic diet supplemented with vitamin $\mathbf{C}$ and the corresponding values for chicks given the same diet without supplementation.

\section{RESULTS}

The results of Expts $\mathrm{I}-3$ are given in Tables $\mathrm{I}-3$ respectively.

Bone ash. Tibia ash weight per unit body-weight was not influenced by the absence of vitamin D during the rst week (Table 1 ), but it was associated with a marked reduction after 2 weeks. The addition of ascorbic acid to the rachitogenic diet appeared both to hasten and to intensify this effect (Table r), although the change was not

\section{Table 1. Expt 1. Influence of vitamin $C$ on the skeletal response to vitamin $D$ deficiency}

(Mean values with their standard errors for groups of ten chicks)

\begin{tabular}{|c|c|c|c|c|}
\hline \multirow[b]{2}{*}{ Group } & \multicolumn{2}{|c|}{$\begin{array}{c}\text { Tibia ash wt } \\
(\mathrm{mg} / \mathrm{l} 00 \mathrm{~g} \text { body-wt) }\end{array}$} & \multicolumn{2}{|c|}{ Epiphyseal plate width (mm) } \\
\hline & Ist week & and week & Ist week & 2nd week \\
\hline Control & $91 \pm 3$ & $120 \pm 4$ & $0.76 \pm 0.06$ & $0.94 \pm 0.06$ \\
\hline Vitamin D-deficient & $90 \pm 4$ & $100 \pm 5$ & $0.79 \pm 0.04$ & $I \cdot 90 \pm 0.31$ \\
\hline $\begin{array}{l}\text { Vitamin D-deficient + ascorbic acid } \\
(44 \mathrm{mg} / \mathrm{kg} \text { diet })\end{array}$ & $85 \pm 3$ & $92 \pm 3$ & $0.99 \pm 0.07^{*}$ & $2 \cdot 12 \pm 0.24$ \\
\hline
\end{tabular}

* Difference from value for the vitamin D-deficient group significant $(P<0.05)$.

Table 2. Expt 2. Composition of dry, fat-free cortical bone at $\mathrm{I} 4$ days of age

(Mean values with their standard errors for groups of twenty chicks)

Group

Control

Vitamin D-deficient

Vitamin D-deficient + ascorbic acid

(44 $\mathrm{mg} / \mathrm{kg}$ diet)

Vitamin D-deficient + ascorbic acid (220 $\mathrm{mg} / \mathrm{kg} \mathrm{diet)}$

$\begin{array}{ccc}\begin{array}{c}\text { Bone ash } \\ (\%)\end{array} & \begin{array}{c}\text { Citric acid } \\ (\mu \mathrm{g} / \mathrm{r} 00 \mathrm{mg} \\ \text { bone })\end{array} & \begin{array}{c}\text { Hydroxyproline } \\ (\mu \mathrm{g} / \mathrm{ro0} \mathrm{mg} \\ \text { bone })\end{array} \\ 63.8 \pm 0.3 & 991 \pm 42 & 2160 \pm 118 \\ 58.4 \pm 0.7 & 869 \pm 38 & 2294 \pm 144 \\ 58.5 \pm 0.5 & 898 \pm 24 & 2202 \pm 182 \\ 60.2 \pm 0.4 * & 869 \pm 40 & 2076 \pm 126\end{array}$

* Difference from value for the vitamin D-deficient group significant $(P<0.05)$.

statistically significant. This effect of ascorbic acid was not evident in Expt 3 (Table 3); however, it should be noted that a different level of the vitamin was used in the latter experiment. A most interesting observation in Expt 3 was the different response of the cancellous and compact regions of the tibia to the added vitamin $C$. When ascorbic 
acid was added to the rachitogenic diet compact bone ash per unit of body-weight was slightly increased, whereas cancellous ash was decreased, although the difference was not statistically significant (Table 3 ). Calculation of the relative amounts of cancellous and compact ash in the total tibia ash showed the same effects. Compared with the controls, vitamin $\mathrm{D}$ deficiency alone resulted in a significant decrease in the amount of cancellous bone in the tibia, and the addition of vitamin $\mathrm{C}$ enhanced this effect to a significant degree (Table 3). Determinations of ash percentage illustrated a similar trend. Vitamin D deficiency resulted in a reduction in ash percentage in both cancellous and compact regions, while the administration of vitamin $\mathrm{C}$ further decreased the percentage of cancellous ash and partially increased the compact ash percentage (Table 3). This latter change, though not striking, substantiates the earlier observation (Table 2) showing a significant increase in cortical ash in rachitic animals given ascorbic acid at the higher level. The suggestion that ascorbic acid may affect different regions of the bone in different ways was thus supported by all three assessments in Expt 3 .

Table 3. Expt 3. Influence of vitamin $C$ on the skeletal response to vitamin $D$ deficiency at 7 and $\mathrm{I}_{4}$ days of age, as observed in the tibia

(Mean values with their standard errors for groups of ten chicks)

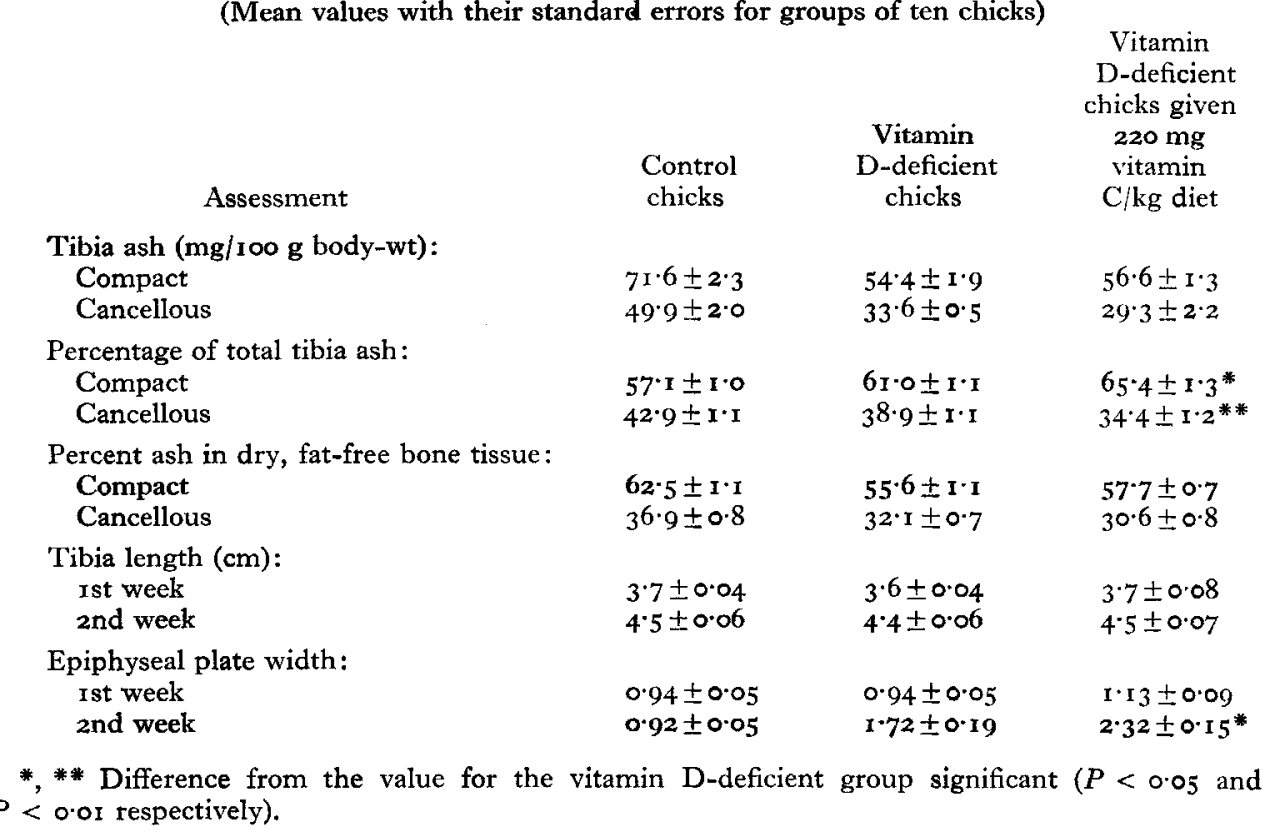

Bone measurements. Despite the bone ash effects, it was apparent that neither vitamin D nor ascorbic acid influenced tibia length within the 2-week experimental period (Table 3 ). Since there was significantly less bone ash in the deficient groups (Table I) it follows that the effectwas on calcification. It should be noted that bone ash measurements were also made at the end of the Ist week in Expt 3 (Table 3), but the findings are not presented here because no differences were observed.

The effect of the dietary treatments on the epiphyseal plate width was similar in 
Expts $I$ and 3 (Tables $I$ and 3 ). It appeared that the presence of dietary ascorbic acid was associated with an earlier and a more extensive response to the vitamin $D$ deficiency.

Chemical analyses. The concentration of citric acid in the bone was reduced by the vitamin $\mathrm{D}$ deficiency, but no further change was effected by the addition of ascorbic acid (Table 2). Hydroxyproline levels were not changed in any instance. Mean plasma ascorbic acid levels (mg/roo $\mathrm{ml}$ ), with their standard errors, for eight chicks from each dietary treatment were as follows: control $2 \cdot 26 \pm 0.06$; vitamin D-deficient $I \cdot 7 \mathrm{I} \pm 0 \cdot \mathrm{I}_{4}$ and vitamin D-deficient plus ascorbic acid $(220 \mathrm{mg} / \mathrm{kg}$ diet) $2 \cdot 32 \pm 0.07$. Thus the vitamin $\mathrm{D}$ deficiency was associated with a highly significant decrease $(P<0.01)$ in the level of ascorbic acid in the plasma, and the level was restored to that of the controls by dietary additions of ascorbic acid. Since these results were recorded, an additional study has been conducted which revealed a $23 \%$ decrease in plasma ascorbic acid after I4 days on a rachitogenic diet (unpublished observations).

\section{DISCUSSION}

The association of vitamin $\mathrm{D}$ deficiency with a decrease in bone calcification in growing animals is well documented (Neuman \& Neuman, 1958). However, the observation that cancellous and compact areas were not equally affected by this deficiency (Table 3 ) is of interest. The significant reduction of cancellous ash per unit of total tibia ash appears to support earlier work concerning skeletal response to physiological changes. Hunter \& Aub (1927) first presented evidence that the parathyroid hormone influenced the mobilization of newly deposited calcium stores. Later Bauer, Aub \& Albright (1929) showed that such stores were probably located in the bone trabeculae. If it is assumed that vitamin $\mathrm{D}$ deficiency reduces calcium absorption and thereby reduces serum ionic calcium, thus stimulating the secretion of the parathyroid gland ( $\mathrm{Au} \&$ Raisz, $\mathrm{I}_{965}$ ), it is probable that the initial area of attack would be the cancellous bone. In the present study, the chicks were just beginning to exhibit rachitic signs and it seems reasonable to assume, therefore, that the parathyroid effect was still directed predominantly towards the cancellous tissue, which could explain in part the greater relative reduction of cancellous bone in the tibia.

However, the main effects of the vitamin D deficiency appear to have been: (a) a reduction in the ossification of the epiphyseal plate leading to an increased width of the plate, $(b)$ a reduction in the calcification of new cancellous bone, $(c)$ a reduced remodelling of cancellous to cortical bone, resulting in less total bone ash, an increase in the relative amount of cortical bone and cortical bone ash compared to cancellous and a reduction in the degree of calcification of both types of bone. Addition of vitamin $C$ appeared to enhance all these effects.

This influence of ascorbic acid is not immediately explicable. It is accepted that vitamin $\mathrm{C}$ is necessary for normal osteoblastic activity (Bourne, 1956), being particularly involved in matrix formation. Recently we have noted that chicks given a control diet exhibited elevated serum calcium, acid phosphatase and hydroxyproline levels within $4 \mathrm{~h}$ following the intraperitoneal injection of ascorbic acid (unpublished 
results). Thus it is possible that ascorbic acid stimulated either bone matrix formation, bone resorption or both processes.

It may be argued that, even though a significant reduction in serum ascorbic acid occurred in the vitamin D-deficient chicks $(2 \cdot 25$ to $1 \cdot 7 \mathrm{I} \mathrm{mg} / \mathrm{I00} \mathrm{ml})$, the latter level is high compared to that in most animal species (Todhunter \& McMillan, I946), and thus changes in skeletal tissue should not be attributed to this factor. However, it should be pointed out that the most obvious lesions of scurvy are those related to changes in the connective tissue of cartilage, bone and dentine. Thus even minor reductions in ascorbic acid may influence skeletal metabolism. Further, the fact that avian species have a higher serum ascorbic acid level than mammals may reflect a greater physiological requirement.

It is apparent that the added ascorbic acid had no influence on either the citric acid or hydroxyproline contents of the cortical bone (Table 2), and it seems probable that the cortical tissue was mostly laid down before the vitamin $\mathrm{D}$ deficiency became serious.

The final point of interest concerns the growth in length of the tibia (Table 3 ). Since there were no differences between the three groups, it can be assumed that bone growth in length was not influenced. Whether shaft diameter or cortex thickness was altered was not determined. In view of the sharp decrease in bone ash percentage in both deficient groups, it was apparent that vitamin D exerted the major influence in the regulation of bone calcification.

\section{REFERENCES}

Au, W. Y. W. \& Raisz, L. G. (1965). Am. J. Physiol. 209, 637.

Bauer, W., Aub, J. C. \& Albright, F. (rg29). Y. exp. Med. 49, 445.

Bourne, G. H. (1956). The Biochemistry and Physiology of Bone. New York: Academic Press Inc.

Briggs, G. M., Combs, G. F., Friedman, L., Fritz, J. C. Lillie, R. J., Nelson, J. W., Quackenbush, F. W. \& Titus, H. W. (1956). Feed Age, May issue.

Hunter, D. \& Aub, J. C. (1927). Q. Fl Med. 20, 123.

Martin, C. J. \& Axelrod, A. E. (1953). Proc. Soc. exp. Biol. Med. 83, 461.

Natelson, S., Pincus, J. B. \& Lugovoy, J. K. (1948). F. biol. Chem. 175, 745.

Neuman, W. F. \& Neuman, M. W. (1958). The Chemical Dynamics of Bone Mineral. Chicago: Un versity of Chicago Press.

Roe, J. H. \& Kuether, C. A. (1943). Y. biol. Chem. 147, 399.

Thornton, P. A. \& Brownrigg, D. (I96I). F. Nutr. 75, 354.

Thornton, P. A., Weber, C. W. \& Moreng, R. E. (I959). F. Nutr. 69, 33.

Todhunter, E. N. \& McMillan, T. J. (1946). f. Nutr. 3I, 573. 